\title{
A gerência recente do endividamento público brasileiro
}

\author{
PEDRO MAIA DA CUNHA \\ MÁRCIO G. P. GARCIA*
}

The recente Brazilian public management.

We use two frameworks to analyze the recent Brazilian public debt management. The first one encompasses the Brazilian optimal public debt management analysis through the examination of the correlations among the main variables to which the public debt is indexed. The second seeks to address the consequences of recent Brazilian economic policies, such as international reserves accumulation through sterilized interventions by the Central Bank and excessive capitalization of federal financial institutions. Those policies have important, albeit often ignored, fiscal impacts, which became important to determine the current size, maturity and composition of the public debt stock.

Keywords: optimal public debt management; Brazil, public bonded debt.

JEL Classification: H63; E58.

\section{INTRODUÇÃO}

A gerência da dívida pública brasileira sempre suscitou grandes debates econômicos no país, seja por conta de seu impacto direto nas contas do governo, pelo histórico recente marcado pela declaração de moratória durante o governo Sarney em 1987, pela quase repetição deste evento em outros momentos - 1997 e 2002 ou simplesmente pelo surgimento de temores sobre uma eventual insustentabilidade no longo prazo, de tempos em tempos. Por conta das mudanças de política macroeconômica vividas pelo país desde o Plano Real, o tema da eventual não sustentabilidade do endividamento brasileiro deixou de ser premente diante da

\footnotetext{
* Este artigo originou-se da monografia de conclusão do curso de economia (PUC-Rio) do primeiro autor, orientada pelo segundo. London School of Economics. E-mail: pedromaia.c@gmail.com, PUC-Rio e CNPq. E-mail: mgarcia@econ.puc-rio.br. Submetido: 28/Agosto/2010; Aprovado: 3/Março/2011.
} 
atual conjuntura econômica, mas o mesmo não ocorre quando se trata do impacto fiscal da dívida sobre as contas públicas.

No contexto internacional, a crise financeira de 2007-2008 renovou o interesse econômico sobre o tema do endividamento trazendo consigo diversos novos desafios de política econômica. Além de suscitar a discussão, seu desenrolar e as respectivas respostas das autoridades fiscais e monetárias à crise tiveram outros importantes impactos econômicos que originaram movimento de migração de vasto volume de capital das economias centrais para as economias periféricas, por conta do baixo nível recorde de juros, poucas perspectivas de crescimento e temor em relação ao crescente endividamento nas primeiras, configurando o que ficou conhecido na literatura como "fatores de push".

No cenário nacional, a contínua melhora da imagem do Brasil junto aos investidores por conta de fatores como estabilidade política, econômica e social, além da demografia e das perspectivas de crescimento, sustentado sobre vasta gama de recursos naturais, que, quando analisados sob um viés comparativo em relação a outros mercados emergentes, acabam por compor um quadro de atração de grande volume de capitais estrangeiros completamente distinto do existente na década anterior, constituindo os "fatores de pull".

A retomada do crescimento econômico empurrada pelos fortes incentivos fiscais e parafiscais, adotados pelo governo após a crise financeira, começa a impactar consideravelmente o quadro de endividamento. Limitado pela baixa poupança privada do país e pela política fiscal conduzida pelo governo voltada para aumento dos gastos correntes e estagnação do investimento público, faz-se necessária a expansão da poupança externa e, tautologicamente, do déficit em conta-corrente, que financiado por fluxos de capital estrangeiros implicaria a continuidade do cenário de câmbio apreciado.

Ao mesmo tempo o Banco Central iniciou uma política de recomposição de reservas internacionais que já as levou do patamar de USD 50 bilhões para a casa dos USD 250 bilhões em apenas cinco anos, superando todas as regras propostas pela teoria econômica como níveis desejáveis de reserva, através de intervenções esterilizadas no mercado cambial ${ }^{1}$. Entretanto, essas seguidas intervenções têm um custo fiscal considerável para o país, medido pelo diferencial de juros entre a taxa paga pelo Banco Central para rolar as operações compromissadas que esterilizam os impactos monetários das compras cambiais, e que constituem também dívida mobiliária federal, e a taxa de aplicação das reservas cambiais. Esse acúmulo de reservas, absorvido sob a forma de endividamento via operações compromissadas implica, além de tudo, encurtamento significativo da maturidade da dívida. Logo, torna-se necessária uma reflexão sobre os benefícios da continuidade dessa política.

Tendo em conta esses desdobramentos da economia nacional é importante que analisemos o que a teoria econômica prescreve como composição ótima da dívida segundo os modelos de suavização orçamentária intergeneracional de forma a po-

\footnotetext{
${ }^{1}$ Em dezembro de 2011, as reservas internacionais já haviam ultrapassado os USD 350 bilhões.
} 
der qualificar as políticas que, conduzidas não só pelo Tesouro Nacional, mas também pelo Banco Central, impactam diretamente o perfil do endividamento.

\section{REVISÃO DA LITERATURA}

A literatura econômica sobre gerência ótima de dívida pública privilegia a abordagem de minimização de risco em frente à de minimização de custos, desde que consideradas condições justas de risco/retorno, em modelos de gerações imbricadas (overlapping generations). Segundo o princípio conhecido como Equivalência Ricardiana, endividamento público e aumento de impostos são formas alternativas de financiamento do governo, já que a criação de um passivo através da emissão de títulos públicos deverá ser enfrentada, em algum momento futuro, com o recolhimento de impostos da população (mantida a trajetória de gastos públicos). Como sugerido em Barro (1979), a premissa da existência de fricções econômicas, ideia sobre a qual se assenta o conceito da suavização da carga tributária como política ótima de tributação e endividamento em um ambiente determinístico, tem importância fundamental para o desenvolvimento da teoria de maximização do bem-estar público. Nesse sentido, a existência de distorções tributárias justificaria uma preocupação adicional com o timing dos impostos, que pode afetar o bem-estar social, já que uma alta volatilidade da carga tributária produz, na média, custos maiores. Sendo assim, a suavização tributária em um ambiente estocástico requer que a taxação seja contingente ao estágio da economia no ciclo econômico, o que, por sua vez, exige também que a dívida seja contingente a essas diferentes fases, como mostram Lucas e Stokey (1983). Em resumo, a dívida, em condições ideais, deveria apresentar características pró-cíclicas, ou seja, exigir maiores pagamentos em períodos de expansão do ciclo e menores desembolsos em tempos de retração econômica, de forma a não obrigar o governo a variar a tributação ao sabor dos diferentes choques macroeconômicos.

Os agentes econômicos financiadores do déficit do governo, no entanto, têm naturalmente preferência por ativos de remuneração contracíclica, aceitando, assim, menores retornos em troca desse tipo de seguro contra choques reais. Sendo assim, uma abordagem da teoria calcada na minimização de custos iria prescrever a emissão desse tipo de instrumento em detrimento do objetivo de minimização de riscos, cuja consequência é o pagamento de um prêmio aos investidores. O fato de ser a taxação compulsória, ao contrário da natureza voluntária do investimento em títulos da dívida pública, justifica a compra de seguro dos investidores como a política mais adequada, já que o objetivo final do governo não é a minimização dos custo em si, mas, sim, a redução das distorções da taxação sobre as alocações de consumo e trabalho dos contribuintes.

Distorções tributárias e/ou distorções no mercado de crédito são as principais fricções que justificam a prescrição da aquisição desse seguro como uma forma de redistribuir o risco dos contribuintes para os investidores, agentes econômicos mais capacitados a lidar com ele. Fisher (1983) sublinha a problemática da restrição de 
crédito argumentando que, assumindo a existência de mercados imperfeitos para capital humano, as pessoas que recebem suas rendas exclusivamente do trabalho estão em pior situação para se proteger de flutuações macroeconômicas do que aqueles que têm acesso aos mercados financeiros. Adicionalmente, Missale (1999) afirma que, dentro de um arcabouço neoclássico onde a tributação distorce as escolhas de trabalho e investimento, a minimização das distorções tributárias deve ser o objetivo principal da gerência da dívida.

Para esse propósito, Missale (1999) busca definir o tipo de título mais adequado à realidade de cada país. Seus resultados finais apontam para títulos nominais como melhor instrumento de proteção se choques de produtividade e/ou de gastos públicos prevalecem, uma vez que choques negativos de oferta e aumento nas despesas, que pioram, ambos, a situação orçamentária do governo, levariam também a menores retornos da dívida nominal por conta da inesperada e concomitante pressão inflacionária deles decorrente. Se, no entanto, choques monetários são predominantes, o melhor seguro é provido por títulos indexados ao nível de preços, já que choques de demanda agregada induzem a uma correlação positiva entre produto e inflação. Tendo em vista a maior persistência dos choques de oferta e também o fato de a política monetária responder majoritariamente a choques de demanda, em condições normais títulos nominais devem ser privilegiados.

No que tange à maturidade do endividamento, as variáveis a serem observadas são os riscos e custos de refinanciamento, de vital importância em episódios de sudden stops, especialmente em economias emergentes. Barro (1997) prega o alongamento da maturidade como forma de isolar o orçamento público de choques nas taxas de juros.

Uma abordagem voltada para a minimização de custos só é defensável se o prêmio de risco exigido pelos investidores se torna muito maior do que aquele refletido pelo risco implícito do endividamento. Tal situação é sintoma de problemas de risco moral e de credibilidade, que impossibilitam emissões cujo objetivo seja a minimização de risco, por conta da adoção pelo governo de uma estratégia de administração da dívida do tipo beat the market. Exemplo típico de tal estratégia é a comunhão perniciosa entre autoridade fiscal e monetária que, de forma a reduzir o valor real de um endividamento prefixado, passa a adotar comportamento leniente com pressões inflacionárias.

Além disso, como a tentação de gerar surpresas inflacionárias é positivamente correlacionada com o tamanho da dívida, como diz Bohn (1991), com a maturidade, um alto nível de endividamento frequentemente impõe sérias restrições ao alongamento da maturidade da dívida, já que a credibilidade da autoridade monetária passa a ser contestada.

Como é de esperar, o conceito de composição ótima da dívida se mistura com o de sustentabilidade, cuja análise é feita através de critérios variados na literatura. Indicador amplamente aceito é a razão entre dívida atual e o valor presente dos superávits orçamentários futuros, computados conservadoramente. Se o resultado da razão for superior a 1 , a sustentabilidade do endividamento passa, então, a ser questionada (FMI, 2003). 
A dinâmica da dívida, no entanto, responde a variáveis interconectadas e de natureza estocástica. Levando em conta tal fato, Garcia e Rigobon (2004) constatam, em um estudo aplicado ao caso brasileiro, que, em um cenário de estresse, a estrutura de correlações das variáveis de interesse para a dinâmica do endividamento do país tende a se alterar de tal forma a provocar uma inflexão da trajetória da dívida, tornando-a insustentável sem que, para isso, nenhuma deterioração fiscal tenha necessariamente concorrido.

Especificamente para o caso de economias emergentes, Reinhart, Rogoff e Savastano (2003) constatam justamente a existência de um fenômeno ao qual atribuem o nome de debt intolerance, que pode ser interpretado na prática como a causa da exacerbação dessa pró-ciclicalidade em momento de reversão dos fluxos de capitais. Os autores concluíram que depois de passada a fase do ciclo de menor aversão ao risco e maior fluxo de capitais para países emergentes, a maior parte desses países tende a se endividar excessivamente e declarar moratória. A declaração do default tenderia a enfraquecer as instituições do país de tal forma a aumentar a probabilidade de reincidência de calote no futuro. Por conta disso, não existiriam patamares de endividamento intrinsecamente seguros para todos os países, pois eles mesmos variariam de um para outro.

Mendoza e Ostry (2007), por sua vez, apresentam visão conflitante com a tese exposta acima. Examinando a solvência fiscal em países avançados e emergentes, concluem que a observância da condição de que a correlação entre um choque de aumento do endividamento e a resposta do governo sob forma de elevação do superávit primário seja positiva é, em geral, satisfeita para ambos os grupos. O comportamento irresponsável, na verdade, seria característico do grupo de países de elevado endividamento, em contraposição ao que ocorre a países pouco endividados, indicando que a intolerância à dívida ocorre não por conta do histórico de ocorrências semelhantes, mas sim pela inevitabilidade de uma moratória ou dos custos políticos e sociais crescentes, fruto dos ajustes necessários como resposta ao aumento do estoque da dívida.

A partir dos arcabouços discutidos nesta seção, passamos à próxima tentando analisar o comportamento das variáveis de interesse para condução de política ótima de endividamento. Tal análise passa pela avaliação das correlações entre os choques mais comuns à economia brasileira e os indexadores de endividamento disponíveis. Seguindo essa lógica, aumento de volatilidade e maior correlação com choques deve implicar redução de exposição a tais indexadores.

\section{ANÁLISE DE PERFIL ÓTIMO PARA O CASO BRASILEIRO}

A teoria econômica propõe a suavização da carga tributária como solução para a minimização dos riscos orçamentários inerentes à gerência da dívida pública. Recomendar-se-ia, portanto, evitar variações frequentes na taxação a fim de reduzir as distorções já geradas por ela. A Tabela 1 nos apresenta a volatilidade de dois dos mais importantes indicadores a que o rendimento da dívida está atrelado. 
Três períodos são observados. A data inicial escolhida é julho de 1994, referente ao marco de lançamento do Plano Real. O primeiro corte é feito em janeiro de 1999, com o abandono da política de câmbio fixo e a subsequente desvalorização cambial. Finalmente, o segundo corte se refere ao início do primeiro governo Lula, marcando o início da reversão das trajetórias de taxa de câmbio e risco soberano, cujas escaladas refletiam os temores do mercado sobre a política econômica a ser implantada por um provável governo petista.

Observa-se a queda consistente, durante esse período, da volatilidade da inflação, medida pelo desvio-padrão e aqui representada pelo IPCA. Tal comportamento deveria apontar, na tendência, para uma redução ao longo desses anos da emissão de dívida indexada a níveis de preços e uma crescente exposição a títulos nominais, cuja volatilidade dos pagamentos é reduzida com a queda da volatilidade da inflação.

O comportamento do câmbio, ao contrário, é dúbio. Em um primeiro momento, com o fim do controle sobre a taxa de câmbio, a volatilidade disparou. É esse tipo de evento que justifica, na teoria econômica, a política que observamos desde então de forte redução do montante da dívida cuja remuneração é dada de acordo com o comportamento do câmbio.

Embora essa volatilidade tenha sido reduzida ao longo da última fase analisada na tabela, tal mudança não teve reflexo na política adotada pelo governo, já que, mesmo reduzida, ainda se encontra em nível bastante alto, o que de certa forma reflete a política cambial que o país adota desde 1999.

Tabela 1

\begin{tabular}{|l|c|c|c|l|}
\hline \multirow{2}{*}{} & \multicolumn{3}{|c|}{ Volatilidade (Desvio-Padrão) } & \multirow{2}{*}{ Desvio-Padrão e Composição da Dívida } \\
\cline { 2 - 4 } & $\begin{array}{c}1994: 07 \text { a } \\
1998: 12\end{array}$ & $\begin{array}{c}1999: 01 \text { a } \\
2001: 12\end{array}$ & $\begin{array}{c}2003: 01 \text { a } \\
2009: 11\end{array}$ & \\
\hline IPCA & 0.82 & 0,544 & 0,336 & $\downarrow$ Desvio-Padrão: $\uparrow$ Dívida Nominal \\
\hline Câmbio & 1,318 & 11,494 & 4,428 & $\downarrow$ Desvio-Padrão: $\uparrow$ Dívida em Moeda Estrangeira \\
\hline
\end{tabular}

A Tabela 1, embora capaz de apontar uma tendência a ser adotada na administração da dívida, tem como premissa necessária à validade de sua análise a necessidade de que a composição da dívida esteja situada no estágio ótimo. Ou seja, a tendência apontada requer que o perfil da dívida em questão seja aquele recomendado pela teoria no momento exatamente precedente à mudança da volatilidade. Sendo assim, devemos buscar um instrumento complementar mais robusto para o caso provável da composição do endividamento não ser a ótima em cada instante de tempo.

Por essa razão, normalmente mais usada é a análise do perfil do endividamento sob o prisma da Tabela 2, que é capaz de prescrever não a tendência, mas sim o instrumento mais recomendado para cada situação. As correlações apresentadas na Tabela 2 são inspiradas no estudo promovido por Goldfajn e De Paula (1999), quando foram obtidas a partir das covariâncias estimadas dos resíduos de um VAR 
(Vetor Autorregressivo) com duas defasagens. As variáveis em questão são: taxa de inflação (IPCA), despesas reais do Tesouro Nacional excluindo-se os encargos da dívida, câmbio nominal e PIB mensal dessazonalizado. Por estarem medidas em nível com base 100 em julho de 1994, o valor das correlações não oferecem interpretações simples sobre sua magnitude. Estamos, por ora, mais interessados no sinal que apresentam.

O uso do resíduo do VAR como fonte dos dados para o cálculo das correlações se justifica por configurar uma medida de dependência preferível à correlação simples, já que é capaz de quantificar inovações não esperadas pelos agentes envolvidos de uma maneira mais refinada. Com esse tipo de metodologia, excluem-se os efeitos atribuídos às realizações passadas das variáveis em questão, que poderiam ser antevistos pelo mercado.

A ideia principal que permeia esse tipo de análise dá conta de que como despesas e receitas não são constantes, o governo deve tentar proteger (hedgear) sua dívida através da emissão de títulos cujos rendimentos estariam completamente condicionados aos gastos e receitas do governo. No entanto, problemas de alinhamento de incentivos impedem que isso seja feito na prática, o que leva o agente governamental encarregado da administração da dívida a explorar as correlações entre as diversas variáveis macroeconômicas a fim de escolher as mais adequadas ao condicionamento da sua dívida.

Esse risco orçamentário pode ser separado em suas várias componentes. Quando a correlação entre gastos e inflação é positiva, um aumento de despesas tende a vir acompanhado de inflação crescente. Portanto, é recomendável a emissão de maior quantidade de títulos nominais, cujo rendimento real é menor com o aumento da inflação.

Quanto à correlação entre produto e inflação, por sua vez, caso seja positiva, isto é, se uma queda do produto fosse, normalmente, também acompanhada de um arrefecimento da inflação, títulos indexados seriam uma boa opção, já que as despesas com encargos da dívida seriam menores justamente em um período de arrecadação reduzida.

A correlação entre câmbio e gastos do governo, quando positiva, tende a sugerir a emissão de títulos denominados em moeda nacional, já que a desvalorização cambial traz pressão sobre os gastos justamente quando esses já estariam, por si sós, em patamar elevado.

Finalmente, a correlação entre câmbio e produto quando positiva, ou seja, uma apreciação cambial normalmente é acompanhada por uma recessão, aponta para a escolha da moeda estrangeira como indexador dos títulos emitidos. Isso ocorre, pois uma queda no produto seria acompanhada de menor exigência de pagamentos de juros da dívida. 
Tabela 2

\begin{tabular}{|c|c|c|c|c|c|c|}
\hline \multirow{4}{*}{} & \multicolumn{5}{|c|}{ Correlações } \\
\cline { 2 - 7 } & \multicolumn{3}{|c|}{ G } & \multicolumn{2}{c|}{ PIB } \\
\cline { 2 - 7 } & $\begin{array}{c}1994: 07 \text { a } \\
1998: 12\end{array}$ & $\begin{array}{c}1999: 01 \text { a } \\
2001: 12\end{array}$ & $\begin{array}{c}2003: 01 \text { a } \\
2009: 11\end{array}$ & $\begin{array}{c}1994: 07 \text { a } \\
1998: 12\end{array}$ & $\begin{array}{c}1991: 01 \text { a } \\
2001: 12\end{array}$ & $\begin{array}{c}2003: 01 \text { a } \\
2009: 11\end{array}$ \\
\hline \multirow{2}{*}{ IPCA } & $-0,030$ & 0,146 & $-0,030$ & 0,129 & 0,022 & 0,129 \\
\hline Câmbio & $-0,090$ & $-0,096$ & $-0,090$ & 0,015 & $-0,177$ & 0,015 \\
\hline
\end{tabular}

$$
\begin{aligned}
& \text { IPCA }+ \rightarrow \text { Dívida Nominal } \\
&- \rightarrow \text { Dívida Indexada } \\
& \text { Câmbio }+\rightarrow \text { Dívida em Moeda Nacional } \\
&-\rightarrow \text { Dívida em Moeda Estrangeira }
\end{aligned}
$$

$$
\begin{aligned}
& +\rightarrow \text { Dívida Indexada } \\
& +\rightarrow \text { Dívida Nominal } \\
& +\rightarrow \text { Dívida Moeda Estrangeira } \\
& \text { - } \rightarrow \text { Dívida Moeda Nacional }
\end{aligned}
$$

Uma análise superficial da tabela 2 acima apresentada poderia nos levar inicialmente a algumas avaliações inconclusivas. É bem verdade, que o valor mais significante para a prática presente de política econômica é aquele referente ao período mais recente, por razões óbvias. No entanto, a correlação entre as variáveis no intervalo recente não está dissociada de uma evolução temporal, o que podemos observar nos gráficos abaixo que mostram as correlações rolantes de 48 meses entre as variáveis presentes na Tabela 2.

Gráficos 1, 2, 3 e 4: Correlação entre IPCA e Despesas do Governo (1), IPCA e PIB (2), Câmbio e Despesas do Governo (3) e Câmbio e PIB (4)
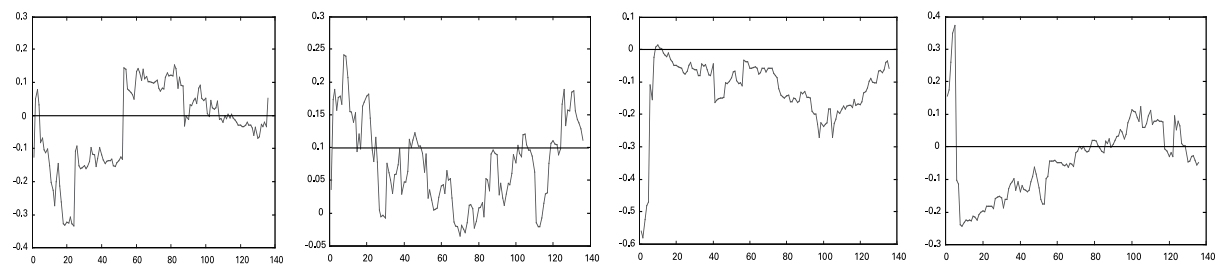

A correlação levemente negativa entre IPCA e gastos governamentais aponta justamente para a continuação da política praticada pelo Tesouro Nacional, desde 2003, de aumento da parcela da dívida cujos rendimentos são prefixados. Embora tal correlação pareça circundar a média zero, o que deixaria o Tesouro indiferente entre indexação da dívida e uso de títulos nominais, a correlação positiva e crescente entre inflação e PIB, como se observa no Gráfico 2, justifica a indexação do endividamento ao IPCA.

Da mesma maneira, a correlação negativa entre câmbio nominal e gastos e positiva entre câmbio nominal e PIB recomendam igualmente o aumento da exposição da dívida à moeda estrangeira. Uma justificativa plausível para tal recomendação é o atual estágio das contas externas do país, que tendem a manter a apreciação cambial nos próximos anos. Por outro lado, precaver-se contra os fenômenos 
de sudden stop, comuns até 2002, recomendaria justamente o oposto, como explicaremos mais à frente.

O elevado desembolso de juros da dívida aliado à política fiscal expansionista praticada hoje pelo governo implicam redução da poupança nacional e aquecimento excessivo da demanda. Tal movimento recai sobre o setor externo sob a forma de déficits correntes, ou seja, poupança externa. Some-se, ainda, o início de um novo ciclo de aperto monetário ocorrido a partir de 2010, implicando maiores desembolsos com juros, e os ingredientes para maior apreciação cambial estão todos presentes.

A condição necessária para que esse equilíbrio perdure está sendo, até aqui, plenamente satisfeita, com a continuidade do otimismo dos investidores internacionais quanto às perspectivas de crescimento da economia brasileira, o que propicia grandes fluxos de capital para o país, via conta financeira do Balanço de Pagamentos.

Algumas ressalvas essenciais, no entanto, devem ser feitas sobre a maior exposição da dívida à taxa de câmbio. A natureza das crises financeiras vividas pelos países emergentes durante as décadas de 1990 e 2000 teve também, certamente, efeito sobre a gerência da dívida pública. Políticas de estabilização sem sucesso, desconfiança dos mercados, sudden stops com fuga maciça de capitais estrangeiros seguidos de forte recessão econômica, marcaram essas crises deixando latente um enorme trauma nos países emergentes. Em muitos casos, para completar, por carência de credibilidade de suas políticas cambiais ortodoxas ou por maior facilidade e/ou menor custo de financiamento, a emissão de dívida em moeda estrangeira prevaleceu sobre a emissão de dívida denominada em moeda nacional. Isso gerou, uma vez chegada a crise, enormes pressões orçamentárias justamente em um momento já extremamente recessivo.

Além disso, uma análise mais detalhada das tendências observadas nos gráficos das correlações rolantes nos apontaria para um resultado distinto, em um futuro breve, continuado tal padrão de evolução de comportamento. Enquanto a correlação entre câmbio e despesas parece esboçar um aumento consistente durante os últimos quatro a cinco anos, a correlação entre câmbio e PIB aponta para uma tendência recente de queda. Persistindo tais movimentos, deve-se esperar uma inversão dos sinais das correlações e, concomitantemente, da recomendação para a emissão de dívida.

Devemos sempre guardar ressalvas quanto a estudos de correlações em períodos prolongados, uma vez que a média retratada por elas não reflete o risco incorrido em épocas específicas de crise, quando a inversão de correlações deixa de ser evento raro para constituir o evento corriqueiro nos mercados. Sendo assim, esse aprendizado sobre a volatilidade dos fluxos de capital internacional e o trauma vivenciado nesses períodos justifica, de certa forma, a desconfiança desses países com a exposição da dívida ao risco de novas desvalorizações cambiais súbitas e a busca por uma dívida completamente denominada em moeda nacional, como a promovida pelo Tesouro Nacional brasileiro. 


\section{COMPARAÇÃO INTERNACIONAL}

A Crise Financeira de 2007 trouxe consigo, no âmbito internacional, uma piora significativa da situação fiscal da grande maioria dos países, principalmente desenvolvidos, exigindo enormes esforços, da parte dos governos, de salvamento de instituições sistemicamente importantes. Por outro lado, mesmo os demais países que não estavam diretamente envolvidos com o enorme boom de crédito direcionado para o setor imobiliário não estavam imunes. O grau de integração entre os mercados financeiros era tal que os derivativos originados a partir dos países problemáticos atingiram instituições financeiras de todo o mundo.

A solução encontrada para lidar com uma crise sem precedentes recentes foi enérgica mundo afora. Enorme expansão monetária e fiscal foi promovida como forma de acomodar o choque e evitar uma contração econômica ainda maior que a observada. Em alguns países isso foi mais fácil, pois havia espaço para manobra por conta de esforços fiscais maiores na fase de bonança (e.g., Chile). Outros países não estavam tão bem preparados, o que levou essas economias a se ressentirem do grande esforço promovido pelos governos durante a crise (e.g., EUA).

O Brasil nesse contexto ficou no meio do caminho. Embora tenha havido nos anos precedentes à crise melhora dos indicadores de endividamento no país, não foi promovido nenhum tipo de ajuste sobre os crescentes gastos correntes do governo. "Sorte" do Brasil, então, foi não estar tão integrado à economia internacional de maneira que os efeitos sentidos foram comparativamente menores e a necessidade de ação imediata do Estado não foi tão grande. Mesmo assim o governo expandiu gastos aumentando sua presença na economia sob o pretexto de ação contracíclica.

Sendo assim, embora a situação fiscal do país tenha se deteriorado no biênio de 2008-2009 e a curva do endividamento tenha dado um pequeno repique, a comparação ainda nos é favorável, quando observamos o Gráfico 5.

Gráfico 5: Endividamento do Governo Geral e Déficit Nominal como \% PIB (Previsão 2010)

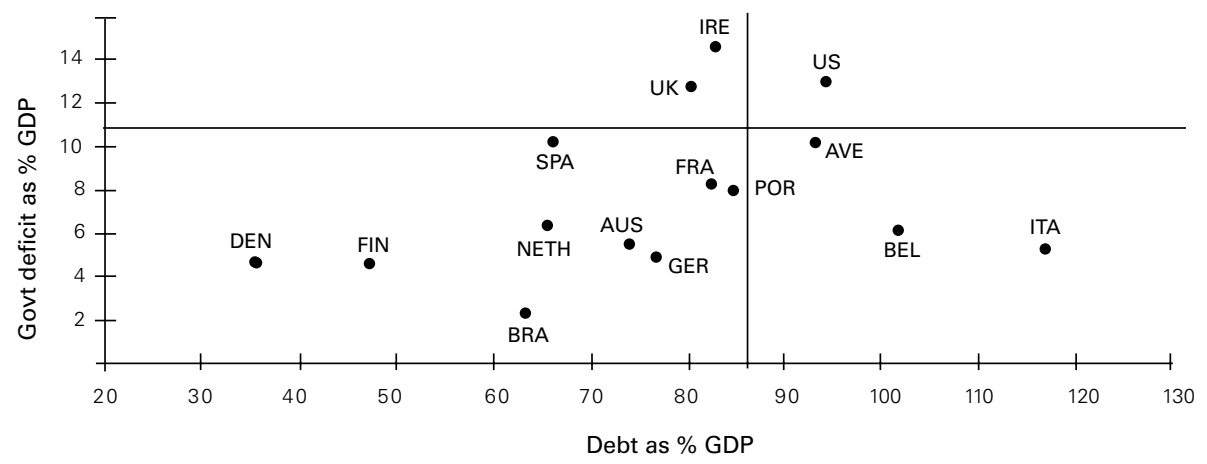

* Média excluindo Brasil. Fonte: European Comission, Credit Suisse, Banco Central do Brasil

O gráfico apresenta as projeções para o endividamento do Governo Geral e para o Déficit Nominal, ambos retratados em porcentagem do PIB. A grande van- 
tagem do país em relação aos demais é ter um déficit nominal razoavelmente controlado (o menor do grupo). A dívida, embora não seja das maiores, será em 2010 bastante superior à de países nórdicos e semelhante à de países bastante afetados pela crise, como a Espanha.

No último trimestre de 2009, o país já retomava novamente, empurrado pelos fortes impulsos fiscais, a trajetória de crescimento. No entanto, esta já começa a enfrentar um dos maiores gargalos da economia brasileira atualmente, a baixa taxa de investimento. A capacidade de investimento do setor público, hoje, é reduzida e agravada continuamente pela expansão dos gastos correntes a taxas superiores ao do crescimento arrecadatório. A situação fiscal do governo contribui, ainda, para a contenção da expansão do investimento privado via taxa de juros elevadíssima. Tal cenário, então, exige que o esforço de investimento seja preenchido pela poupança externa.

Assim, o Brasil, que até 2007 ostentava superávits em transações correntes inicia, a partir de então, um movimento preocupante de rápida reversão daquele quadro. Ilustra bem essa mudança de cenário o fato de, há poucos anos, tanto preocupar a magnitude dos déficits correntes americanos, o que parecia um problema distante à realidade brasileira, e agora estarmos nós alcançando, e mesmo ultrapassando, aquele país em matéria de déficit em transações correntes.

O Gráfico 6 também contribui para a desmistificação da situação brasileira em relação ao resto do mundo. O Brasil lidera a lista dos orçamentos mais comprometidos com o pagamento de juros quando comparado com todos os outros países em questão. É flagrante a magnitude do problema quando se observa a Grécia, às voltas com uma grave crise fiscal e uma dívida pública por muitos considerada insustentável, apresentar despesas com juros muito menores que o Brasil.

\section{Gráfico 6: Despesa com Juros como \% das Receitas} e Déficit Nominal como \% PIB

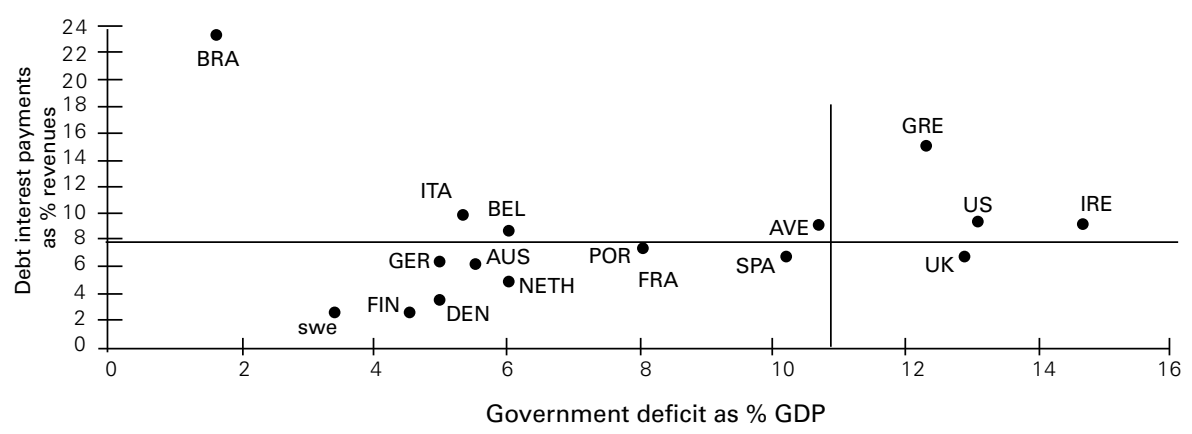

* Média excluindo Brasil, Fonte: European Comission, Credit Suisse, Banco Central do Brasil 
A redução dessa despesa deveria ser uma das metas da política fiscal brasileira. Tal tarefa passa não por uma decisão arbitrária, desconsiderando o sistema de metas para inflação, mas sim por maior controle sobre o aumento de gastos por parte do governo que traga a dívida pública, novamente, a uma trajetória cadente e, em menor grau, por outras reformas que impedem uma queda superior dos juros, como a da remuneração da caderneta de poupança.

\section{INTERVENÇÕES CAMBIAIS, INCENTIVOS PARAFISCAIS E INDICADORES DE ENDIVIDAMENTO BRASILEIRO}

Desde 2006, o Banco Central do Brasil promove uma política agressiva de acúmulo de reservas internacionais. O que se tratava inicialmente apenas como mera recomposição de reservas, então em baixos níveis, passou a despertar o interesse dos analistas na medida em que, um após outro, os índices propostos pela literatura econômica de reserva ótima foram sendo superados sem que houvesse o menor sinal de interrupção de tal política. $\mathrm{N}$ meses de importação, regra de Guidotti-Greenspan (razão entre reservas e dívida de curto prazo maior ou igual a 1) e o mais recente proposto por Jeanne e Rancière (2008) não explicam o atual patamar das reservas. Este último, o mais rigoroso para o caso brasileiro, sugere $9 \%$ do PIB como o marco que determinaria o seguro.

Desde 2007 acima dos 9\% do PIB, as reservas, na verdade, se aproximam de um patamar asiático de $15 \%$ do PIB. Se é bem verdade que ajudaram o país a superar a Crise Financeira de 2007-2008 sem maiores traumas, deve-se indagar o porquê de elas continuarem aumentando fortemente mesmo depois de serem suficientes para lidar com o que muitos consideram a pior crise econômica dos último oitenta anos.

A contrapartida dessas intervenções esterilizadas promovidas pelo BC é o aumento da Dívida Pública Brasileira. Ao comprar dólar no mercado spot ou futuro o Banco Central emite operações compromissadas para enxugar a base monetária, contendo, assim, qualquer possível canal de transmissão da política cambial para o comportamento dos preços. Essas operações, no entanto, diminuem a maturidade da dívida, por configurarem instrumento de prazo curto, bem como contribuem para o aumento do custo do endividamento. De maneira preocupante, já compõem um quarto do total da DPMF, como mostrado no Gráfico 7 abaixo sob série de título "SELIC 1". 


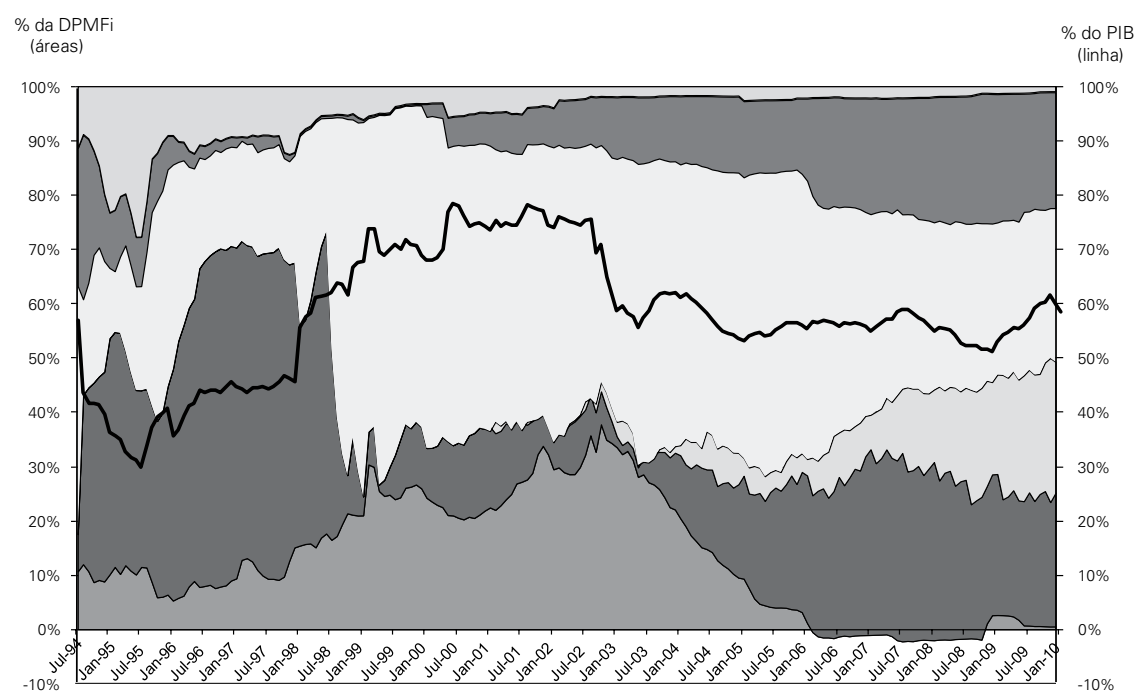

\begin{tabular}{|llr|}
\hline Outros & Índices de Preços & Selic2 \\
Selic 1 & Pré-Fixados & Câmbio \\
DPMFi (\% do PIB) - IPCA & & \\
\hline
\end{tabular}

Fonte: Banco Central do Brasil

Claramente, tal política deverá ser revista em algum momento próximo. Os benefícios marginais da acumulação de reservas, mantidas majoritariamente em papéis do Tesouro dos EUA, diminuem na medida em que excedem por muito as necessidades do país em se assegurar contra choques externos (sudden stops). Já os custos marginais são extremamente elevados, dados pelo rendimento das operações compromissadas, a taxa Selic, muito superior à taxa externa de juros.

Injustificável, o custo incorrido com essa política em nada tem a ver com aquele recomendado pela teoria de endividamento ótimo, já que não reduz o risco orçamentário e na verdade até o aumenta, já que o ativo acumulado como seu resultado tem rendimento inferior ao passivo correspondente. Além disso, retarda a queda de juros ao atrasar a apreciação cambial e o correspondente efeito benéfico desta sobre a inflação.

As repercussões fiscais negativas já são inclusive sentidas, como exposto no Gráfico 8, com o aprofundamento de uma cunha existente entre a taxa de juros implícita da dívida e a taxa SELIC. Desde 2007 acima da taxa básica de juros, a taxa implícita segue impassível mesmo diante da queda considerável dos juros na economia no último ciclo de afrouxamento monetário. 


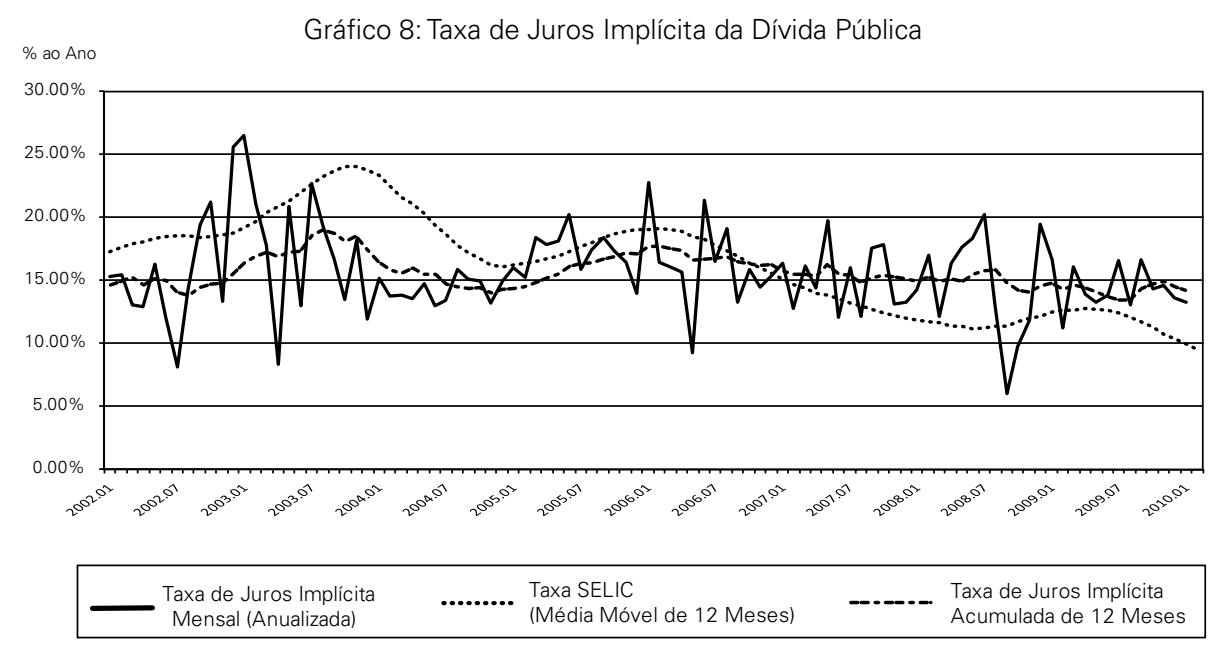

Fonte: Banco Central do Brasil

Tal disparidade entre taxa de juros básica da economia e taxa de rendimento da dívida pública pode nos levar a relativizar a validade do conceito de Dívida Líquida, já que essa tende a crescer consideravelmente acima da taxa SELIC, cujo rendimento está normalmente associado àquele da Dívida Pública Mobiliária Federal Interna (DPMFI). Teria, portanto, alguma validade teórica para a análise de conjuntura do custo do endividamento público a criação do conceito de Dívida Equivalente, definida como aquela que, à taxa implícita da Dívida Mobiliária Federal Interna, geraria a mesma despesa anual de juros da Dívida Líquida.

Teríamos, portanto:

$\mathrm{DL}$ = Dívida Líquida; DE = Dívida Equivalente;

I = Taxa implícita anual da Dívida Líquida; s = Taxa SELIC over anualizada

$$
\begin{aligned}
& D L . l=D E . s \\
& D E=\frac{l}{s} . D L
\end{aligned}
$$

Assim, a evolução da Dívida Líquida e da Dívida Equivalente se daria da seguinte forma:

$$
\begin{aligned}
& D L_{t}=D L_{t 0} \cdot \prod_{i=t 0}^{t-1}\left(1+l_{i}\right) \\
& D E_{t}=D E_{t 0} \prod_{i=t 0}^{t-1}\left(1+s_{i}\right)
\end{aligned}
$$


A partir dessa formulação chega-se ao Gráfico 9, abaixo, segundo o qual a Dívida Equivalente já seria 50\% maior que a Dívida Líquida hoje.

Gráfico 9: Dívida Líquida x Dívida Equivalente

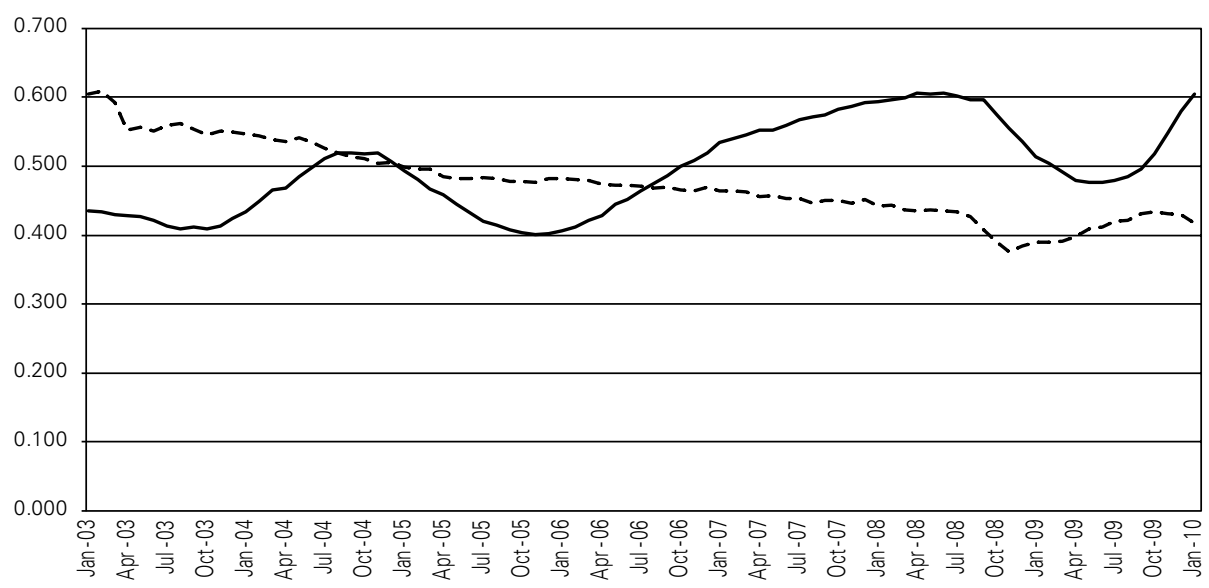

- - Dívida Líquida _ Dívida Equivalente

Fonte: Banco Central do Brasil

É claro que a formulação mostrada acima sofre por conta de algumas premissas a ela subjacentes, bastante fortes. Fundamentalmente, supõe-se que a razão entre as taxas de juros em questão permaneceria no futuro aproximadamente estável. Logo sua validade teórica seria equivalente a um simples retrato da realidade, não servindo assim para sustentar previsões mais robustas sobre o comportamento da Dívida Pública. Entretanto, sua validade como instrumento de análise não deve ser descartada já que fornece uma informação relevante sobre o custo corrente da dívida líquida de forma bastante intuitiva.

Mantida a diferença entre as taxas de juros em questão, a tendência natural das duas séries (DE e DL) seria a de se igualarem no futuro. Logo, quanto mais cedo este encontro ocorresse, mais relevante seria a formulação do conceito de Dívida Equivalente. Quanto mais distante, maior a chance de que alguma mudança nas variáveis em debate alterasse o percurso de ambas as séries.

Vale, então, nos perguntarmos quando, dada a atual conjuntura brasileira, Dívida Líquida e Dívida Equivalente se igualariam.

Supondo l e s constantes:

$$
\begin{aligned}
& D L_{t 0}(1+l)^{t}=D E_{t 0}(1+s)^{t} \\
& \frac{(1+l)^{t}}{(1+s)^{t}}=\frac{D E_{t 0}}{D L_{t 0}}
\end{aligned}
$$


Substituindo (1) em (2), temos:

$$
\begin{aligned}
& \frac{(1+l)^{t}}{(1+s)^{t}}=\frac{l}{s} \\
& t=\frac{(\ln l-\ln s)}{(\ln (1+l)-\ln (1+s))}
\end{aligned}
$$

E é aqui que, embora teoricamente limitado, o conceito demonstra seu valor prático. Alertando para o fato de que, mantida a atual cunha entre a taxa implícita da Dívida Líquida e a taxa SELIC over anualizada, a Dívida Líquida teria seu tamanho aumentado em $50 \%$ em um prazo um pouco menor que sete anos, tal instrumento cumpre o papel para o qual propomos a sua utilização.

Além desta, outra importante questão metodológica para a efetividade da comparação dos indicadores de endividamento brasileiro com os dos demais países que muitas vezes escapa até mesmo aos analistas mais atentos é a discussão técnica sobre a condução da contabilidade da dívida bruta brasileira. Os elevados estímulos parafiscais promovidos pelo governo, como os enormes empréstimos do Tesouro Nacional ao BNDES, e mudanças no cômputo da dívida bruta do governo geral vêm alimentando esse debate.

A pretexto de fomentar o crescimento e aumentar os investimentos, o Governo Federal decidiu expandir o balanço do BNDES em R \$ 100 bilhões em 2009 e, em 2010, já anunciou nova emissão de títulos no total de R $\$ 80$ bilhões para novos empréstimos $^{2}$. O grande problema desta medida é que, uma vez que os empréstimos viabilizados pelo BNDES por tais repasses têm sua remuneração revertida para o Tesouro, implicando saldo contábil zero, a dívida líquida não se altera, não refletindo o real custo dos aportes.

Esse custo real é o diferencial, em termos de juros, entre o custo da captação feita pelo Tesouro para possibilitar o aporte no BNDES e o custo dos empréstimos cedidos pelo banco de desenvolvimento. Enquanto o TN remunera os detentores de seus títulos com uma taxa um pouco superior à SELIC, o BNDES concede empréstimos a taxas subsidiadas lastreadas pela TJLP (Taxa de Juros de Longo Prazo). O subsídio, não raro, supera os 6\%. No entanto, mesmo onerando as contas públicas de forma significativa, dada a magnitude dos aportes feitos, tal impacto não aparece no indicador de dívida líquida, já que em seu cálculo são descontados os ativos do total dos passivos.

Buscando englobar esses incentivos parafiscais ao conceito de Dívida Líquida, Loyola e Salto (2010) propuseram um novo indicador. Este seria calculado através do desconto das Reservas Internacionais do volume total da Dívida Bruta. Obser-

\footnotetext{
${ }^{2}$ Em março de 2011, o ministro da Fazenda anunciou novo empréstimo de R \$55 bilhões em 2011 e sinalizou novos empréstimos, de menor monta, para anos futuros.
} 
va-se, entretanto, que nos últimos anos tal novo indicador apresenta trajetória crescente e, portanto, contrária à suave tendência de queda da Dívida Líquida.

Como reflexo desta distorção observada, dissemina-se entre os analistas a observação minuciosa do indicador da dívida bruta do Governo Geral, em detrimento da popularidade do indicador de Dívida Líquida, uma vez que o indicador bruto é capaz de desmascarar esses efeitos fiscais perversos.

A escolha da DBGG (Dívida Bruta do Governo Geral) em detrimento da DLSP (Dívida Líquida do Setor Público consolidado) não dirime todas as dúvidas na comparação dos dados brasileiros com os internacionais. A causa disso é a existência de duas séries de DBGG, fornecidas pelo Banco Central, calculadas a partir de metodologias distintas.

A diferença entre as duas séries é, basicamente, o tratamento dado aos títulos livres do Tesouro na carteira do BC. Enquanto a metodologia antiga inclui estes no total do endividamento, revelando uma interpretação do Banco Central como agente independente do Governo Geral, cuja função principal é a condução da política monetária, a metodologia nova não trata aqueles títulos como dívida bruta. A justificativa para a não inclusão dos títulos livres é que eles são concedidos ao BC não para financiar o Tesouro, mas sim como forma de viabilizar a condução da política monetária, uma vez que o BC perdeu, em 2000, por conta da Lei de Responsabilidade Fiscal, o direito de emitir títulos próprios.

Embora não tenha despertado maiores atenções quando da sua criação, em fevereiro de 2008, essa nova metodologia, dois anos depois, no início de 2010, iniciou uma trajetória completamente destoante da série antiga, como mostra o Gráfico 10.

Gráfico 10: Evolução das Dívidas Bruta do Governo Geral (Metodologia Antiga e Nova) e Liquida do Setor Público - \% do PIB

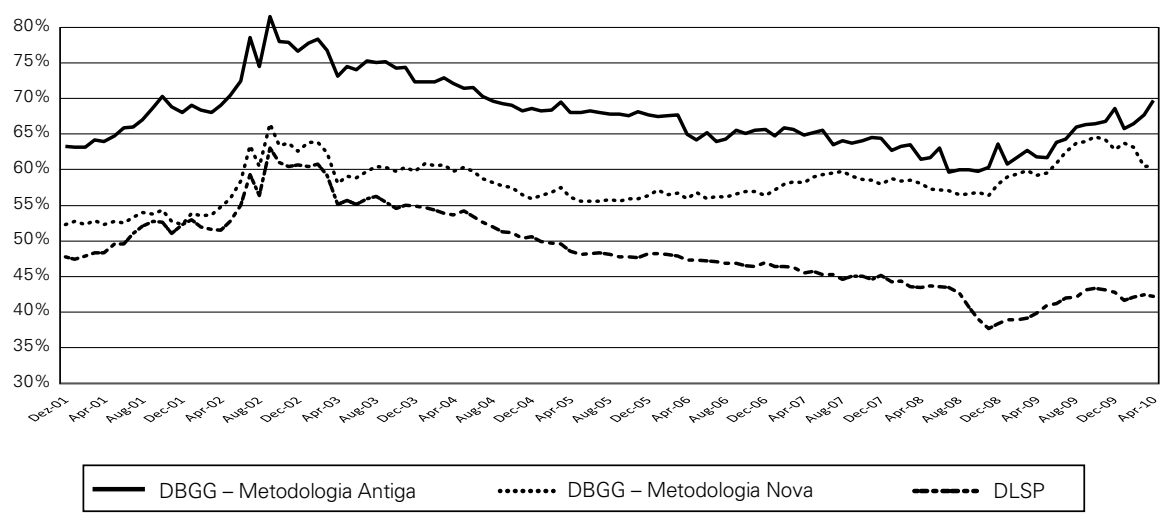

Fonte: Banco Central do Brasil

Entre fevereiro e março de 2010, como visto acima, a diferença entre as duas séries aumentou abruptamente em $\mathrm{R} \$ 128$ bilhões, aproximadamente $5 \%$ do PIB. A razão dessa movimentação assimétrica entre os dois indicadores da DBGG foi a 
reversão da política de liberação de compulsório realizada durante o auge da crise financeira internacional, no ano de 2008, como forma de melhorar a liquidez do sistema financeiro nacional.

Durante a vigência dos menores compulsórios, o que se observou foi a migração de volume semelhante aos R \$ 100 bilhões liberados para as operações compromissadas. Isto é, na prática a liberação apenas levou os bancos a comprarem operações compromissadas a fim de aferir retorno sobre o montante de capital até então não remunerado, não impactando, assim, ao menos diretamente, aumento da liquidez no sistema.

Quando o nível anterior dos compulsórios foi restabelecido, ocorreu o movimento contrário. Enorme volume de operações compromissadas foi desfeito para o cumprimento da exigência, liberando aproximadamente R \$ 67 bilhões em títulos do TN na carteira do BC, diminuindo assim, em igual montante, a DBGG segundo a nova metodologia. Curiosamente, a DBGG, segundo a metodologia antiga, aumentou em volume semelhante concomitantemente a essa queda observada na nova forma de cálculo. A explicação para tal aumento, entretanto, é de natureza diversa, sendo resultado do pagamento de $\mathrm{R} \$ 55$ bilhões feito em 30 de março de 2010 (de acordo com a portaria \#186 do Tesouro Nacional) do resultado negativo das operações com reservas cambiais do BC no segundo semestre de 2009, fruto da apreciação do real em frente ao dólar.

Entendidas tais diferenças, a metodologia antiga, embora tenha comportamento mais volátil, por conta das constantes variações do volume de títulos livres na carteira do $\mathrm{BC}$, ainda parece mais adequada no que concerne à comparação internacional e à visão de $\mathrm{BC}$ independente predominante na maioria dos países avançados.

\section{CENÁRIOS DE LONGO PRAZO}

Passamos agora a uma nova etapa, tentando traçar alguns prováveis cenários de evolução da política econômica brasileira e as respectivas consequências sobre o indicador da dívida bruta ao longo dos próximos oito anos. Para tanto, fizemos uso do método de Monte Carlo de simulação estocástica ${ }^{3}$ de forma a tornar o exercício útil para a avaliação dos riscos envolvidos.

As variáveis de interesse neste estudo são expectativas de crescimento do PIB, da inflação medida pelo IPCA, do resultado nominal do governo, do crescimento das reservas internacionais e dos empréstimos a instituições financeiras oficiais. Para as três primeiras, atribuímos funções de distribuição de probabilidade triangulares, na maioria das vezes assimétricas, e às duas últimas foram imputados valores coerentes com o histórico recente de evolução das mesmas variáveis.

\footnotetext{
${ }^{3}$ Os gráficos foram omitidos no texto para efeito de síntese, privilegiando o uso de tabelas. Sua disponibilizacão poderá ser feita prontamente mediante pedido aos autores.
} 
Dada a complexidade do estudo, que em sua forma mais rigorosa deveria lançar mão de um cuidadoso estudo das interações e correlações entre as distribuições em questão, optou-se pelo uso de expectativas levemente otimistas de maneira a resguardar a validade, ao menos parcial, de um eventual resultado não tão positivo para a evolução da dívida brasileira em decorrência das questões levantadas nos capítulos precedentes.

Feitas essas observações, quanto às principais hipóteses do estudo, o cenário central adota a mediana das expectativas levantadas em pesquisa diária feita pelo BC para os dados de crescimento do PIB e IPCA. Sustenta como principal premissa a hipótese de que a política de superávit primário de $3 \%$ do PIB será mantida ao longo dos anos. Além disso, prevê que o crescimento das reservas internacionais seja reduzido à taxa de $10 \%$ ao ano e que o crescimento dos empréstimos a instituições aos bancos oficiais não supere o crescimento do PIB, valores esses bastante menores que os até aqui praticados. Por fim, espera-se que a SELIC real bruta caia gradativamente até 4\% ao ano em 2018 e que já em 2017 inicie-se um ciclo de impactos positivos sobre o resultado fiscal do governo, advindo de ganhos com royalties e participações especiais da exploração da camada pré-sal de petróleo.

A Tabela 3 abaixo mostra justamente o cenário central descrito no parágrafo acima. Sublinhada a escolha de premissas levemente otimistas para efeito de simulação, a tendência apresentada na tabela, de crescimento persistente do endividamento até 2016, revertendo-se apenas depois de computados eventuais ganhos de receita oriundos do pré-sal, é bastante preocupante.

Tabela 3

\begin{tabular}{lccccccccc}
\hline & \multicolumn{8}{c|}{ Dívida Bruta (\% PIB) } \\
\hline Média & $\mathbf{2 0 1 0}$ & $\mathbf{2 0 1 1}$ & $\mathbf{2 0 1 2}$ & $\mathbf{2 0 1 3}$ & $\mathbf{2 0 1 4}$ & $\mathbf{2 0 1 5}$ & $\mathbf{2 0 1 6}$ & $\mathbf{2 0 1 7}$ & $\mathbf{2 0 1 8}$ \\
$\mathbf{5 \% - 9 5 \%}$ & $70.0 \%$ & $71.1 \%$ & $71.5 \%$ & $71.8 \%$ & $72.4 \%$ & $72.3 \%$ & $72.5 \%$ & $72.2 \%$ & $71.7 \%$ \\
\hline
\end{tabular}

Passamos agora, então, a tentar avaliar possíveis cenários de estresse ao quadro anterior. No primeiro deles, a Tabela 4 mostra o que aconteceria se desconsiderássemos uma eventual melhora do resultado fiscal do governo, fruto de um, também eventual, aumento na receita do governo oriundo da exploração do pré-sal. A Tabela 5 abaixo diverge do cenário principal ao prever uma queda mais gradual da SELIC real bruta ao longo do tempo, chegando, em vez de a 4\% em 2018, a 4,5\%. A Tabela 6 , por sua vez, simula uma leve expansão dos empréstimos às instituições financeiras oficiais de $1,5 \%$ acima do crescimento do produto.

Tabelas 4, 5 e 6

\begin{tabular}{|c|c|c|c|c|c|c|c|c|c|}
\hline \multicolumn{10}{|c|}{ Dívida Bruta (\% PIB) } \\
\hline & 2010 & 2011 & 2012 & 2013 & 2014 & 2015 & 2016 & 2017 & 2018 \\
\hline Média & $70.0 \%$ & $71.0 \%$ & $71.3 \%$ & $71.8 \%$ & $72.4 \%$ & $72.3 \%$ & $72.5 \%$ & $72.6 \%$ & $72.5 \%$ \\
\hline $5 \%-95 \%$ & & $70.5 \%-71.5 \%$ & $70.8 \%-72.2 \%$ & $71.2 \%-72.4 \%$ & $71.8 \%-73.1 \%$ & $71.7 \%-72.9 \%$ & $71.8 \%-73.2 \%$ & $71.9 \%-73.2 \%$ & $71.7 \%-73.2 \%$ \\
\hline
\end{tabular}

\begin{tabular}{lccccccccc}
\hline & \multicolumn{8}{c}{ Dívida Bruta (\% PIB) } \\
\hline Média & $\mathbf{2 0 1 0}$ & $\mathbf{2 0 1 1}$ & $\mathbf{2 0 1 2}$ & $\mathbf{2 0 1 3}$ & $\mathbf{2 0 1 4}$ & $\mathbf{2 0 1 5}$ & $\mathbf{2 0 1 6}$ & $\mathbf{2 0 1 7}$ & $\mathbf{2 0 1 8}$ \\
$\mathbf{5 \% - 9 5 \%}$ & $70.0 \%$ & $70.9 \%$ & $71.5 \%$ & $72.2 \%$ & $72.8 \%$ & $73.0 \%$ & $73.2 \%$ & $73.4 \%$ & $73.2 \%$ \\
\hline
\end{tabular}




\begin{tabular}{lccccccccc}
\hline \multicolumn{10}{c}{ Divida Bruta (\% PIB) } \\
\hline & $\mathbf{2 0 1 0}$ & $\mathbf{2 0 1 1}$ & $\mathbf{2 0 1 2}$ & $\mathbf{2 0 1 3}$ & $\mathbf{2 0 1 4}$ & $\mathbf{2 0 1 5}$ & $\mathbf{2 0 1 6}$ & $\mathbf{2 0 1 7}$ & $\mathbf{2 0 1 8}$ \\
\hline Média & $70.0 \%$ & $71.1 \%$ & $71.7 \%$ & $72.1 \%$ & $72.8 \%$ & $72.9 \%$ & $73.3 \%$ & $73.2 \%$ & $72.7 \%$ \\
$\mathbf{5 \% - 9 5 \%}$ & & $70.7 \%-71.5 \%$ & $71.2 \%-72.3 \%$ & $71.6 \%-72.8 \%$ & $72.2 \%-73.4 \%$ & $72.3 \%-73.5 \%$ & $72.4 \%-74 \%$ & $72.4 \%-73.8 \%$ & $72 \%-73.6 \%$ \\
\hline
\end{tabular}

Por fim, a Tabela 7 prevê o que aconteceria caso todos os choques acima acontecessem conjuntamente com um afrouxamento da política de superávit primário, que, nesse caso, cairia leve e gradativamente até atingir $2 \%$ do PIB em 2018. Tal cenário seria o equivalente à manutenção das políticas de governo adotadas até aqui, podendo assim ser considerado como um cenário mais próximo da realidade do que aquele primeiro ao qual nos referimos como central, cujo viés é levemente otimista.

\section{Tabela 7}

\begin{tabular}{lccccccccc}
\hline & $\mathbf{2 0 1 0}$ & $\mathbf{2 0 1 1}$ & $\mathbf{2 0 1 2}$ & $\mathbf{2 0 1 3}$ & $\mathbf{2 0 1 4}$ & $\mathbf{2 0 1 5}$ & $\mathbf{2 0 1 6}$ & $\mathbf{2 0 1 7}$ & $\mathbf{2 0 1 8}$ \\
\hline Média & $70.0 \%$ & $71.1 \%$ & $72.0 \%$ & $72.9 \%$ & $73.9 \%$ & $74.8 \%$ & $76.0 \%$ & $77.7 \%$ & $78.8 \%$ \\
$\mathbf{5 \% - 9 5 \%}$ & & $70.7 \%-71.7 \%$ & $71.5 \%-72.5 \%$ & $72.3 \%-73.6 \%$ & $73.1 \%-74.9 \%$ & $73.7 \%-75.4 \%$ & $75 \%-77 \%$ & $76 \%-78.6 \%$ & $77 \%-80 \%$ \\
\hline
\end{tabular}

O padrão apresentado na tabela acima se revela preocupante na medida em que projeta um quadro de clara insustentabilidade do endividamento bruto do país. Esta insustentabilidade teria a ver com a manutenção da política fiscal expansionista adotada nos últimos anos de governo, refletida em crescimento excessivo do gasto corrente, expansão de reservas e incentivos parafiscais, além de elevados aumentos reais do salário mínimo, que associados a um complicador demográfico anunciado de crescente parcela de população aposentada, resultaria em uma combinação altamente perversa à situação fiscal brasileira.

\section{CONCLUSÃO}

A gerência da dívida pública brasileira tem evoluído muito, constituindo-se em importante componente da estabilidade econômica que vige desde a implantação do Plano Real. A dinâmica do ajuste do perfil da dívida pública àquele ótimo sugerido pela literatura tem sido consistente e as oportunidades de redução de risco orçamentário foram aproveitadas pela STN.

Saindo de um regime de câmbio fixo na década de 1990, quando predominavam os títulos nominais e indexados ao câmbio, passamos, em 1999, para um regime de câmbio flutuante ao qual o Tesouro soube se adaptar depois de alguns pequenos incidentes de percurso. O sistema de metas para inflação entrou em vigor, a volatilidade dos índices de inflação foi reduzida desde então e, com isso, diversificou-se a emissão de títulos através da indexação do rendimento de parcela daqueles a índices de preços. Paralelamente, reduziu-se fortemente a exposição à variação cambial, principalmente depois do susto vivenciado em 2002-2003, com a enorme desvalorização do Real, que serviu de ilustração para o aumento da volatilidade cambial. Atualmente, o Brasil é credor líquido em moeda estrangeira por conta do 
enorme acúmulo de reservas, o que leva uma desvalorização cambial a ter efeitos positivos no balanço do Tesouro, diferentemente do que acontecia no passado.

A STN divulga anualmente o Plano Anual de Financiamento (PAF), quando explicita metas e os meios pelos quais serão alcançadas. Esses objetivos são entendidos, em uma perspectiva ampla, no que se refere à dívida, como "(minimização de) seu custo de longo prazo, concomitantemente com a manutenção de seus riscos em níveis prudentes" (PAF, 2010).

Há algum tempo as metas da STN, que são traçadas a partir de uma modelagem distinta da usada neste artigo e que inclui a probabilidade da ocorrência de eventos de estresse que altere as correlações vigentes em períodos de normalidade, se assemelham em muito às sugeridas pelo estudo conduzido neste trabalho. $\mathrm{O}$ Tesouro demonstra claramente preferência por títulos indexados a índices de preços e busca, também, a redução do passivo em moeda estrangeira, justamente por esse apresentar grande volatilidade em momentos de incerteza. Além disso, outra meta é a redução da dívida vincenda nos próximos doze meses e o alongamento do prazo médio do estoque total de dívida. Embora esses objetivos venham sendo alcançados de forma mais gradual e lenta, já que nosso prazo médio ainda é bastante baixo comparativamente aos padrões internacionais, a tendência das duas variáveis é claramente a mesma traçada no planejamento das ações do Tesouro.

Embora administrada pelo Tesouro, a Dívida Pública sofre impacto das decisões econômicas dos diversos braços do governo. Sendo assim, políticas equivocadas em outras esferas acabam tendo reflexo direto ou indireto sobre o endividamento. Essa é, atualmente, a grande falha de atuação de um governo, onde a política fiscal cria dificuldades para a política monetária que, por sua vez, impacta a gerência da dívida que, paralelamente, tem também que lidar com as dificuldades impostas pela política cambial.

Apesar de apresentar, hoje, endividamento e déficit orçamentários menores do que a média dos países desenvolvidos, extremamente afetados pelos desdobramentos da crise financeira recente, novos problemas parecem surgir para o quadro do endividamento brasileiro. O primeiro deles é aquele referente ao impacto das intervenções cambiais esterilizadas do Banco Central. Essas intervenções que seriam recomendáveis em casos normais de recomposição de reservas, passam a ser danosas para o país por conta de seu elevado custo, quando os benefícios dela provenientes começam a minguar. Tal política já parece ter efeito na taxa de juros implícita da dívida líquida que se mantém inalterada mesmo após sucessivas reduções de juros pela autoridade monetária, ilustrando o aumento do custo de financiamento. Além disso, outro impacto decorrente dessas intervenções é o encurtamento da maturidade da dívida, já que a esterilização das compras cambiais é feita via operações compromissadas cujos vencimentos são bem mais curtos (seis semanas) que os oferecidos por outros instrumentos da dívida pública.

Outro importante problema a ser levantado foi a expansão do que chamamos incentivos parafiscais nos anos de 2009 e 2010 (e que vem continuando até 2012). Enormes aportes a bancos oficiais, principalmente ao BNDES, configuram subsídios à iniciativa privada, e com um viés para a grande empresa, que oneram o orçamen- 
to público, o que, até aqui, já significou um aumento no indicador de dívida bruta de sete pontos percentuais de PIB, trajetória insustentável no longo prazo.

Analisados em conjunto, todos esses problemas, como visto na análise de cenários prováveis de longo prazo, poderiam colocar em dúvida, em um futuro não muito longínquo, a própria sustentabilidade da dívida. A continuidade da política fiscal, parafiscal e cambial até aqui praticada pelo governo aproxima-se, portanto, de um ponto crítico. Ou optamos por uma inflexão de políticas macroeconômicas ou seremos, nós, as vítimas de uma inflexão forçada: a da trajetória da dívida fruto da continuidade das políticas até aqui praticadas.

Cabe ao governo, então, curar a inconsistência entre as políticas monetária e fiscal, sincronizando seus diferentes braços e pernas para galgarmos, com a segurança necessária, novos degraus na escada da estabilidade econômica, obtendo crescimento econômico com inflação sob controle.

\section{REFERÊNCIAS BIBLIOGRÁFICAS}

BARRO, R. (1979), “On the determination of public debt”, Journal of Political Economy 87(6): 940971.

BARRO, R. e D. Gordon (1981), “A positive theory of monetary policy in a natural-rate model”, NBER Working Paper, 807, Novembro.

BARRO, R. J. (1997), “Optimal management of indexed and nominal debt”, NBER Working Paper, 6197, Setembro.

BOHN, H. (1991), “Time consistency of monetary policy in the open economy”, Journal of International Economics, 30: 249-266.

FISCHER, S. (1983), "Welfare aspects of government issue of indexed bonds", in R. Dornbusch and M. Simonsen (eds.), Inflation Debt and Indexation: 223-246. Cambridge, Massachussets: MIT Press.

FMI (2003), World Economic Outlook, Setembro.

GARCIA, M. e R. RIGOBON (2004), “A risk management approach to emerging markets' sovereign debt sustainability with an application to Brazilian data”, NBER Working Paper, 10336, Março.

GOLDFAJN, I. (1995), “On public debt indexation and denomination”, Brandeis University Working Paper, 345.

GOLDFAJN, I. e DE PAULA, Áureo (1999), “Uma nota sobre a composição ótima da dívida pública: Reflexões para o caso Brasileiro”, Texto para Discussão \#411, Departamento de Economia PUC-Rio.

JEANNE, O. e R. RANCIÈRE (2008), “The optimal level of international reserves for emerging market countries: A new formula and some applications”, CEPR Discussion Papers \#6723.

LOYOLA, G. e F. SALTO (2010), "Retrocessos fiscais ameaçam estabilidade”, O Estado de São Paulo, 3 jul. 2010.

LUCAS, R. e N. STOKEY (1983), “Optimal fiscal and monetary policy in an economy without capital”, Journal of Monetary Economics, 12: 55-94.

MENDOZA, E. e J. OSTRY (2007), "International evidence on fiscal solvency: Is fiscal policy responsible?”, NBER Working Paper, 12947, Março.

MISSALE, A. (1999), "Public Debt Management”. Oxford: Oxford University Press.

REINHART, C., K. ROGOFF. e M. SAVASTANO (2003), “Debt intolerance”, NBER Working Paper, 9908, Agosto.

TESOURO NACIONAL, Plano Anual de Financiamento de 2009.

TESOURO NACIONAL, Plano Anual de Financiamento de 2010. 